\title{
A COMPARATIVE ANALYSIS OF WASTE MANAGEMENT SYSTEMS USED FOR ENVIRONMENTAL PROTECTION: NORWAY (Oslo) - ZANZIBAR (Zanzibar)
}

\author{
Cristian Alexandru STEF $\breve{A N E S C U}{ }^{a^{*}}$, Răzvan Cătălin DOBREA ${ }^{b}$, Maria LOGHIN $^{c}$ \\ ${ }^{a, b, c}$ Bucharest University of Economic Studies, Romania
}

\begin{abstract}
As we have fully entered the 21st century our planet has gained several advancements and improvements, while at the same time reaching an unprecedent level of prosperity for most of its inhabitants. At the same time the discrepancies of development between various parts of our planet have never been more visible due to the extraordinary development of all manners of communication and information sources. One of the most visible areas in which such discrepancies are hard to be ignored, due to its far-reaching impact is the management of waste products namely the waste produced by the daily activity of the population - municipal waste.

There are countries which have implemented management systems which result in a net minus quantity of waste - meaning that that specific country imports waste in order to utilize it for its own industries and there are countries which have become storage facilities for the waste generated by other countries. This study has as main purpose a comparison of the systems in such countries from the most developed ones to the ones which are currently the least developed in this area, by taking a look at what the largest waste management companies in Zanzibar and Norway are doing and analyzing their strong and weak point while providing solutions for improvement.
\end{abstract}

KEYWORDS: development, management, waste, management systems, comparison, systems, Zanzibar, Norway.

\section{DOI: 10.24818/IMC/2021/01.19}

\section{INTRODUCTION}

The production of waste is one of the main results of the human activity taken as a whole, and while such generation is inevitable, the manner in which various state and private entities approach the management of such waste is a clear indication of that society's degree of economic development, social responsibility and awareness of the effects of such waste on the environment in general and on human life in particular (Zimring \& Rathje, 2012).

The manner of approach on the management of waste has changed throughout the years from the simple dumping of waste which has a huge impact over the environment to complex management systems which have a zero or negative impact, however there is still a huge difference between the manner in which developed countries such as Norway approach this issue versus the manner in which less developed countries such as Tanzania manage this issue.

This article has as main purpose the presentation of the overall context in which waste is generated including the specific analyzed cases, the description of the existing management strategies and the differences between them, differences arising from the discrepancies in economic development and the proposal of a system which would have as main purpose the reduction of the discrepancies between the two locations.

\footnotetext{
*Corresponding author. E-mail address:stefanescu.c.a@gmail.com
} 


\section{STUDY}

The study is divided into several areas namely: 1) an analysis of the types of waste generated that are the focus of the study; 2) a description of the areas which are the focus of the study and of the waste management strategies used by them; 3) a comprehensive proposal for several solutions aimed at reducing the gap between the two analyzed cases and; 4) a set of conclusions with regards to the two cases.

\subsection{A short analysis of the types of waste generated in regular human activities}

Waste can be classified into several categories depending mainly on: generation source (householdmunicipal, industrial, commercial, construction); type of waste (degradable and non-degradable); degree of reusability (reusable and non-reusable); degree of danger in handling (perilous and nonperilous) (Wheeler \& Glucksmann, 2015; Franceschetti, 2017).

The Waste Management theory states that there is no non-reusable waste, meaning any and all waste with extremely small exceptions (radioactive waste) can be reused, recycled or repurposed. The same theory states that landfills are the final solution and solely for inert construction waste which cannot be repurposed. As such a unitary approach on waste management with the aim of establishing a Municipal Waste Management Strategy for any administrative unit has to take under consideration as a final purpose the elimination of the landfill as a means of disposing of waste.

Since the broad area of Waste Management has many more classifications and types of waste, the analysis of which is not possible in such a paper, the main focus for the current paper will be a small part of generated waste, which however is the largest in terms of quantity generated for most of the planet, namely Municipal Solid Waste or more precisely, the waste generated by households in their daily activity.

Households in their daily activity generate waste from various sources, waste which in a civilized society is collected, separated by type, processed, reused, repurposed and recycled to begin a new cycle of usage. The types of waste generated by households and the quantity of such waste depends mainly on several factors: household income, NGDP for the country in which the household is situated, degree of civil awareness of population, involvement of the local and national authorities.

These types of waste are:

Biological degradable waste - waste generated by food leftovers and food processing. This type of waste can be easily repurposed in residential compost units and turned into compost to be used in gardens, parks, etc. There is also the option in the case of large generation of such waste of bulk collection and turning such waste into electricity through gas digesters; This final option is also applicable and recommendable in the case in which the majority of the generated waste is biodegradable.

Plastic and paper waste - waste generated mostly by packaging of food products and any other purchased products. This type of waste can be recycled after collection by specialized companies and recycled with the final purpose of repurposing into various forms. Such types of recycling include processing plastic products into plastic pellets through mechanical processing or into fuels through pyrolysis processing. Paper waste can be processed and turned into packaging or into insulation for houses by specialized companies. There is a large number of companies throughout the world that are turning such waste into usable products (https://conceptosplasticos.com is one of the most successful examples having won numerous awards for their initiative)

Glass waste - waste generated by bottles mainly and by broken glass products. This type of waste while in the previous years had decreased a lot due to the prevalence of plastic bottles, has started increasing in the last two years due to a switch to a more environmental conscious population which has started using reusable glass bottles.

This type of waste is $100 \%$ recyclable; however, this depends on the collection degree. 
Cloth waste. Depending on the type of cloth it can be repurposed or broken down into fibers and turned into cloth-based products such as blankets or carpets (There is thriving industry doing this in India - https://circularapparel.co/blog/2020/07/13/where-does-textile-waste-go). However, the majority of such waste ends up into landfills due to the lack of specialized processing units.

Construction waste. This type of waste can be separated into two types of waste: reusable and inert non reusable. The reusable waste is the organic one: wood and its derived products mostly - leaves, bark, particle boards, etc. The inert/non reusable is the actual construction waste - tiles, brick, cement, plaster boards, drywall metal studs, nails and screws, etc.

This reusable waste can be mostly repurposed while the portion not suitable for such can be crushed and turned into mulch or other decorative garden products or into wood pellets for usage into wood burning residential heating units or commercial greenhouses.

The inert/non-reusable waste can be further separated into metal waste which can be collected/sold to specialized companies which are processing such waste, while the non-reusable portion must be crushed and can be used either in landfills or as basis for road building.

Most of the construction waste for households comes from renovation performed for residential units and as such the quantities are not significant.

Furniture waste. This type of waste is different from the rest since in itself it generates four types of waste: cloth, metal, wood and plastic since these are the main components used for building of furniture. The options are as follows: either the individual components after separation in specialized centers will be reused according to the above, or the piece of furniture can be taken over by other types of companies and will be repurposed (i.e., chest of drawers can be used as a sink stand or wood entrance doors can be used as sliding interior barn type doors or old wooden windows can be used as picture frames.

Medical waste. This type of waste is classified into hazardous and non-hazardous. The manner of disposal and treatment for each of them is different since the danger posed by each type is different. However, given the generation point for these wastes, the majority of household generated medical waste is hazardous since it consists mainly of used contaminated bandages, needles, syringes and expired medicines.

Human waste. This is the second category of waste generated by households in terms of quantity and it is a category which is not analyzed usually or even put in the same "basket" as the rest of the waste, although, depending on the manner of approach when dealing with it, it can be either the category with the highest or the lowest impact on human life.

Human waste is usually processed into water treatment plants which are usually municipally sized, namely built to cater for the needs of an entire city, while the waste is transported (most of it) through centralized underground pipe systems. The rest of the waste is transported to such facilities by specialized vehicles.

Please take under consideration that all the above are true under ideal conditions and for administrative units which have implemented to the $\mathrm{n}^{\text {th }}$ degree all options of processing waste. However, at this moment this is done only in theory due to various impediments as we shall further demonstrate.

The purpose of this document is to draw a comparison between two diametrical opposed areas of our planet namely between the Municipality of Oslo, Norway and the Municipality of Zanzibar, Tanzania. Both of these municipalities are the capitals of their respective regions/countries with Zanzibar being the capital for the Zanzibar Archipelago (Part of Tanzania in a federal form of organization and the main hub of tourism for the country) and with Oslo being the capital of Norway. 


\subsection{A description of the areas which are the focus of the study and of the waste management strategies used by them}

\section{Oslo}

The capital, main city and most important city in Norway with a GDP of 58 billion USD as of 2019, Oslo has become a model for the municipalities throughout the world in terms of waste management strategies, which above all take under consideration the impact over the environment and its reduction in the normal activity of such a thriving city.

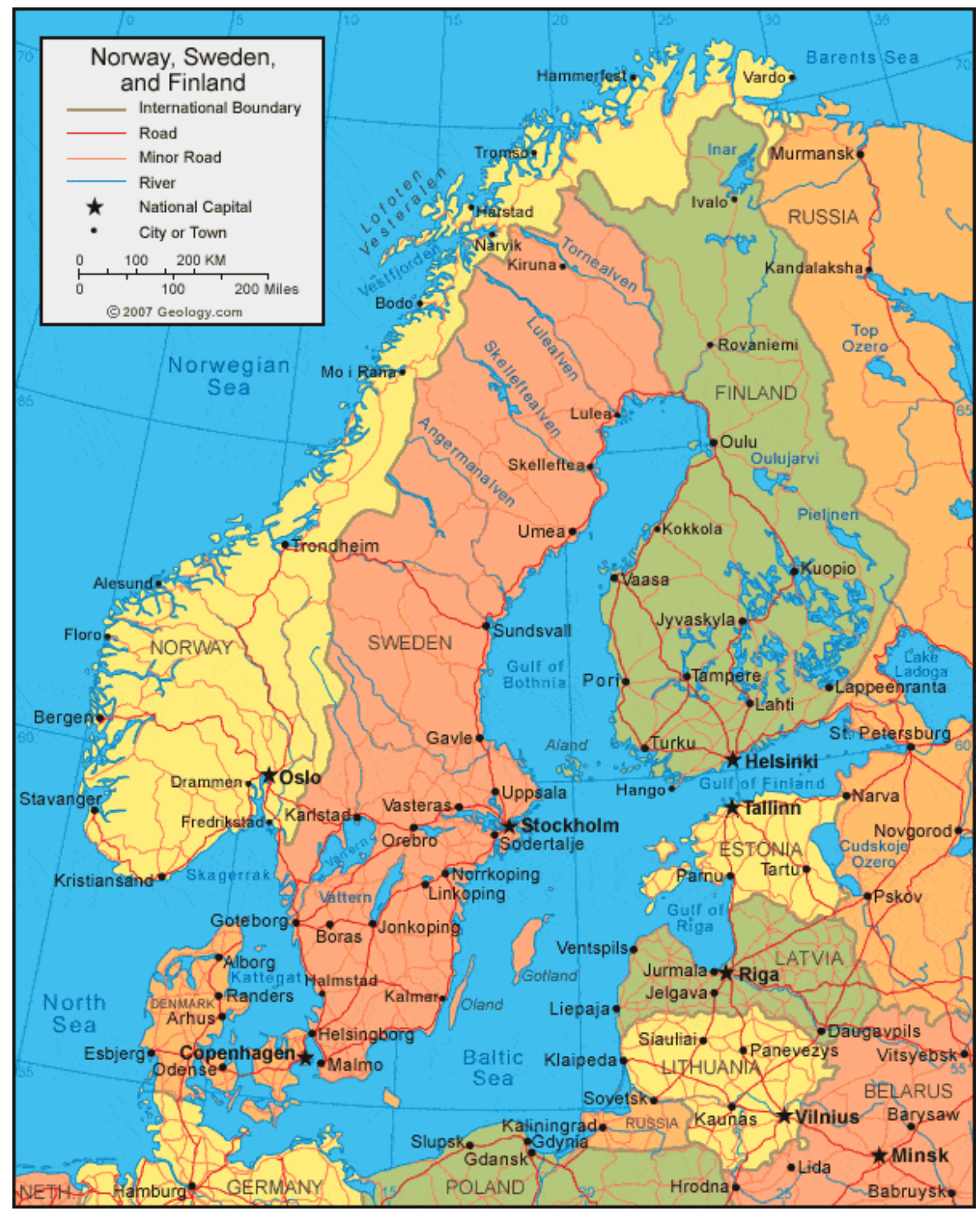

Figure 1. Location of Oslo in relation to Norway

Source: Geology.com

The population of Oslo is of 580000 individuals as of November 2020 (https://populationstat.com/ norway/oslo), while the waste generation rate for each individual was of $0.89 \mathrm{Kg}$ pe capita per day as of 2018. This quantity is decreasing year after year due to the increased practices of recycling as can be seen from the below graph. These figures add up to a quantity of generated waste of around 189000 tons MSW per year. This does not take into account the greater municipal area of Oslo which doubles the population and subsequently the generated waste. 
Oslo has invested heavily into any and all technologies of recycling, sorting, collection and technologies aimed at repurposing the collected waste, while developing the mentality of its inhabitants through learning programs for both children and adults.

At the same time the state developed a system of fines and check points based on averages, which was aimed at increasing the recycling level and creating a collection and recycling mentality.

Specifically, there are 14 recycling stations both large and small, 2 mobile recycling stations and 1022 local collection sites for glass and metal packaging.

Due to this around 57\% of the collected waste is transformed into heat and energy, further used in households and businesses. Actually, the energy produced through the transformation of waste powers all the schools in Oslo.

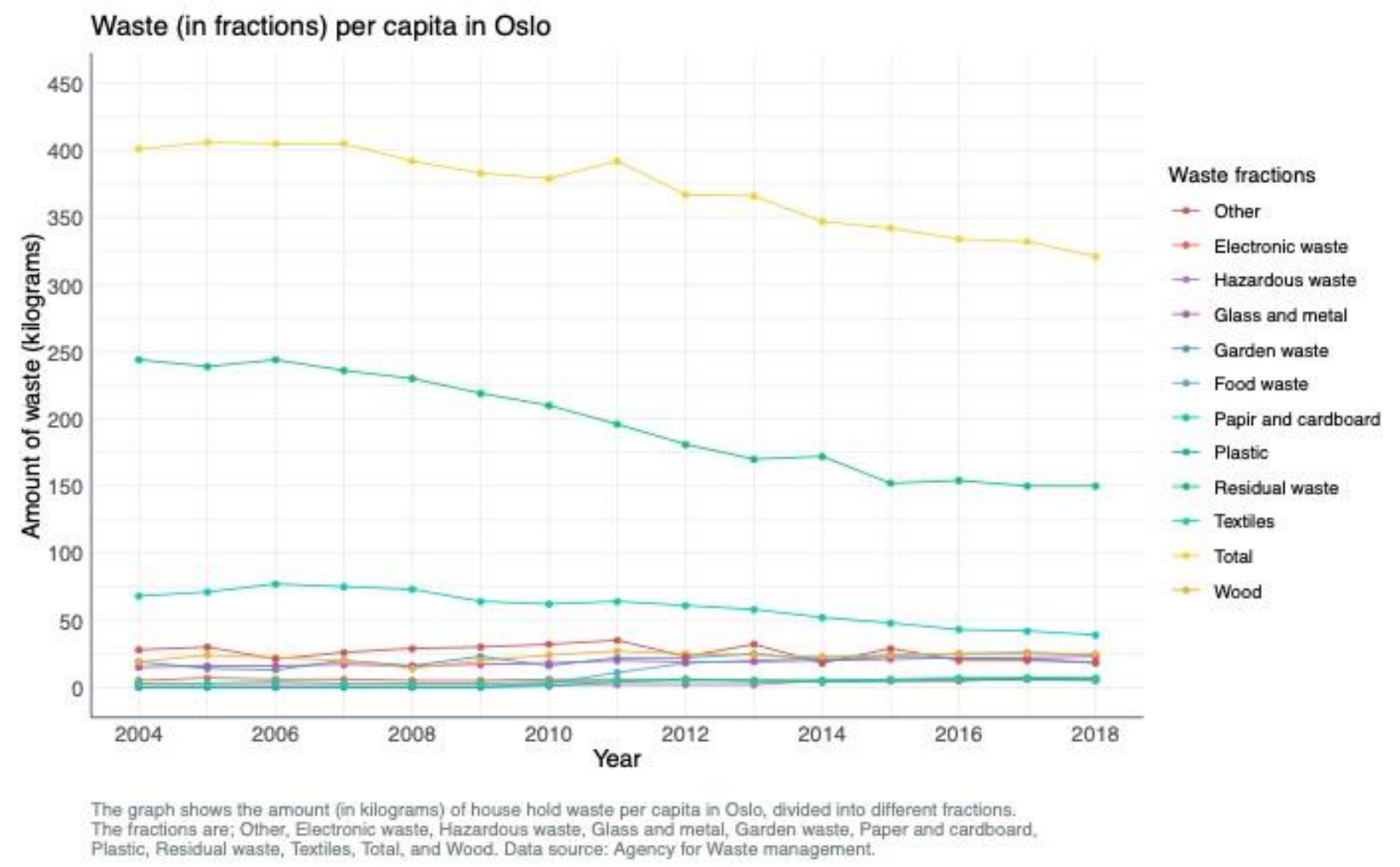

Figure 2. The evolution of waste generation and composition for the city of Oslo Norway. Source:www.oslo.kommune.no/politics-and-administration/statistics/environmentstatus/waste-and-recycling-statistics/

As it can be seen Oslo lies at one extreme end of the waste management strategies with a developing strategy with a required net result of zero non recycled waste with the exception of asbestos and inert wastes.

This was not achieved immediately, but rather following a complex process implemented in a period of years. The first year in which waste was separated by type was 1997 and the system was improved during a 15-year period, resulting in the currently used system.

Two main factors had a large impact on the strategy applied and, on the results, achieved:

1. Effective planning both overall planning and micro planning, meaning all the steps in the collection, usage, recycling, generation and reusage process were analyzed and improved continuously 
2. Segregation of waste based on different colored bags, namely for recyclable items, this system allowing for the ease of processing and possibility of evaluation of generated quantities and further on, evaluation of solutions to be implemented in the management of waste.

\section{Zanzibar}

Zanzibar is the capital of the homonym archipelago (consisting of two islands Unguja - commonly known as Zanzibar Island and Pemba) located in Eastern Africa of the coast of Tanzania, and part of the Tanzanian Republic. It is a mostly self-sufficient republic, loosely affiliated to the mainland, only several areas being managed by the larger government of Tanzania namely military, currency and supply of electricity. For the rest of the management of the archipelago, the population elects its own president and ruling body and manages all local decisions.

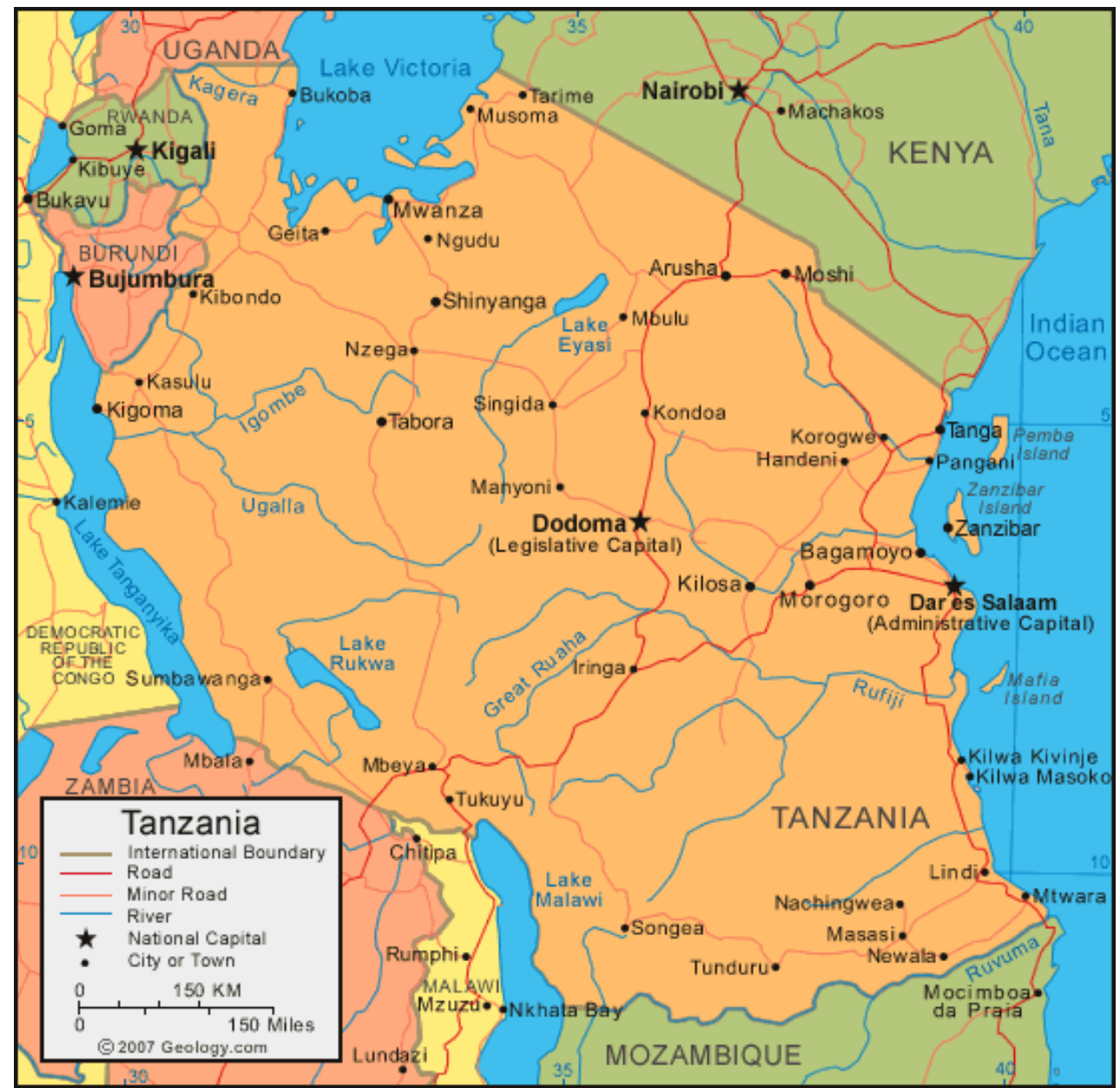

Figure 3. Zanzibar Island part of Zanzibar Archipelago and its relative position compared to Tanzania

Source: Geology.com

The population in the Municipality of Zanzibar is of 403,658 individuals as of March 2021 (https://www.statista.com/statistics/1221854/largest-cities-in-tanzania), while the waste generation rate for each individual was of $0.75 \mathrm{~kg}$ per capita per day (http://roaid.ro/wp-content /uploads/2021/05/IMPACTSTUDY_ZANZIBAR_PREMIUMAUDIT_AUGUST2020_final.pdf) with some $85 \%$ of it being wet waste (biodegradable waste: food scraps, food waste, fruit pulp and plants parts). All this adds up to around 300,000 tons of MSW out of which some 250,000 tons being biodegradable waste suitable for decomposition in anaerobic digestors (Dinh et al., 2020). 
What has to be taken into consideration is the fact that although the figures above are based on information provided by the Revolutionary Government of Zanzibar, these are all extrapolations since actual figures will be available only starting in 2021 (the first full year during which Zanzibar has a controlled high standard landfill which was financed by the World Bank). The current figures do not take into account the informal waste dumping or burning or the waste which is collected and sold to third parties (mostly recyclable materials such as plastic, cardboard and glass to Chinese collection companies which export these to China).

Main industries and income generation for the archipelago are tourism and agriculture. The infrastructure for the islands is almost nonexistent except roads and electricity supply, there is no centralized management of waste, supply of water or any other services.

These lead, at least in the terms of waste management, to a situation which can be summarized as follows:

- There are no centralized, organized collection services except the ones provided to hotels and state institutions;

- There is no formalized payment for any of the collection services that exist;

- The majority of the population on the islands (except the ones in the main city) are burning their waste or dumping it on the side of the roads.

- All human waste is dumped into informal pits or open-air latrines since there is no centralized waste water treatment.

- Except the hotels, nobody is paying to have their waste collected and processed;

The government recognizes the situation as dire and is taking steps to ensure a solution will be available in the future.

Zanzibar sits at the other end of waste management strategies, since there are no implemented strategies, situation which has a huge impact over the environment, population and development of the island.

At this moment there have been studies performed which point towards a solution that would address the two main problems on the island, as while the waste issue is the most visible one, the other problem has an even higher impact on the development and that is the lack of sufficient supply of electricity to deal with the existing and future consumption.

The solution proposed by these studies consists of the development under a partnership between private companies and the local government of a WTE (Waste to Energy) facility which would take the majority of Municipal Solid Waste - not human waste, and transform it into electricity.

This would effectively solve both problems, however the costs associated to such a development are prohibitive and not conductive to implementing such a solution in the near future. At the same time the makeup of the waste generated on the islands also leads to a different solution to be implemented, solution which has a lower cost point and takes advantage of the types of waste generated.

As can be seen in figure 4 the main component of the generated waste in Zanzibar is organic, which is not suitable for a WTE facility as proposed in the initial studies. As such the most effective strategy for the management of the waste generated on the island must include a mix of the following: Digestor Ingestion facility which would process all organic waste (it can also be used to process human waste). Such facility would generate electricity also and it will also provide rich nutrients to be used in agriculture on the island, thus targeting several industries: Energy, Agriculture, Environment with a relative cheap solution. 


\section{MUNICIPAL WASTE COMPOSITION ZANZIBAR ISLAND - ZANZIBAR ARCHIPELAGO}

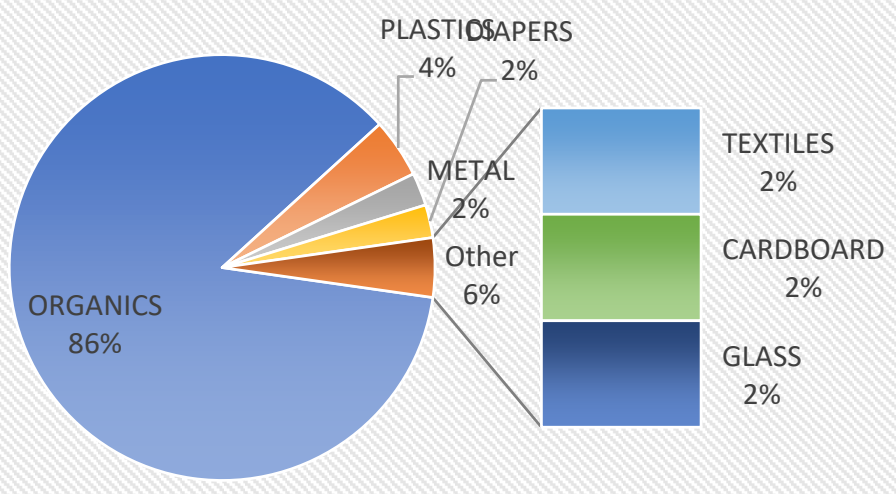

Figure 4. The makeup of Municipal Solid Waste generated on the islands of Zanzibar Archipelago as per a study performed by the Author during 2018-2019 on-site. The study was commissioned by the Romanian Foreign Affairs Ministry through ROAID.

Source: made by authors

Collection and recycling facilities for the plastic, metal, textile, glass and cardboard waste. This has the potential of generating enough income to offset the costs associated to the collection and recycling from the sale of accumulated recovered materials.

Small incinerator with energy production generators attached which would deal with the hazardous waste such as diapers or medical waste.

Setting up of a payment scheme by the population which would include collections services, segregated on types of waste;

All the above can only be achieved if the population is made aware and taught the basics of waste recovery and reusage and the perils of out of control dumping as it happens at this moment. That is why the above measures/solutions have to be doubled by the following:

Setting up a learning program in the schools to increase the awareness of the population with regards to the waste management. This would have an added effect if as the school children in Japan are cleaning their schools, the school children in Zanzibar would take part each month in a cleaning program for the islands - namely picking up trash from the countryside and along the roads.

Setting up on the site of the existing landfill of a waste separation facility which would be used solely for the separation of all collected waste into organic, recyclable waste and construction waste in order to redirect all streams of waste to their appropriate disposal facilities as mentioned above.

As it stands for Zanzibar, any solution which solves the problems is sufficient, however the lack of knowledge coupled with the lack of funds of the local government and the unwillingness of the population to pay for the management of their waste is not a good combination and it leads to wrong, expensive decisions.

\section{RESULTS - A comprehensive proposal for several solutions aimed at reducing the gap between the two analyzed cases}

When analyzing the situation of waste throughout the world, one has to take under consideration the cycle of waste generation in relation with two factors: GDP per capita and the degree of schooling for the specific areas. 
As such there is a direct correlation between the increase of the two factors mentioned above and the decrease of generated waste and the makeup of such generated waste. For example, economies which are under development or third world classified will have a small quantity of waste generated per capita. As the industrialization of said country will increase and the population will have access to more diversified goods the quantity of waste generated per capita will increase, and finally will start to decrease at the moment the said country or municipality will go towards a first world economy.

At the same time the evolution from third world to first world countries has a major impact on the makeup of waste generated by the population. For example, third world countries generate waste which is mostly biodegradable since the products used by them are coming from local agriculture (mostly subsistence) - as can be seen above from the make-up of waste in Zanzibar, while industrialized countries generate a lot more non-biodegradable waste generated by a consumerism industrialized society and the first world countries revert to mostly biodegradable waste since they recycle the majority of their waste as can be seen above for Oslo.

The current practices in the management of municipal waste are different between the two municipalities, however these differences do not stem necessarily from the higher development of Oslo versus Zanzibar, but from the needs for each of them and the manner in which the management of such waste addresses these needs.

In analyzing the management for both of the municipalities, we shall take under consideration both existing practices and planned ones.

Taking into consideration all the above, the best solution available in order to reduce the gap between the two analyzed municipalities is one which will stretch over a period of 10 years with the aim of transforming a third world country mentality of the population with regards to waste generation in a first world country mentality, while at the same time implementing the appropriate cost-effective solutions that would reduce the environmental footprint of the municipal waste generation.

The solutions to be implemented according to the existing best practices (Rathoure, 2019; Chang \& Pires, 2015) and based on the make-up of generated waste on the island are as follows:

Complete analysis of the generated waste: commercial, agriculture, residential, medical, industrial, analysis which would generate the exact quantities (+/-10\% discrepancy) of generated waste for each type. This can be achieved through the usage of local communities

Set up of a training program in schools, state administration buildings and commercial businesses with regards to: waste, collection practices, dangers of not upholding the best practices in this area and achievements possible when upholding these practices.

Setting up of island wide collection services with collections separated by type: recyclable plastic, recyclable glass, recyclable metal, biological and food waste (including construction materials since most of the construction materials used by the population are wood and leaves), medical waste.

Setting up of a sorting station which would collect all waste on the island and separate it on categories with the initial purpose of recycling, repurposing and reusing.

Setting up with the aid of the state of PPP units with the aim of repurposing the sorted waste into materials to be used on the island - for example all recycled glass can be transformed into windows for the schools (none of the schools on the island has windows) or the plastics could be used in making new waste containers.

Setting up of a waste to energy anaerobic digestor unit which is the best solution for processing biological waste (Dinh et al, 2020) which would take all biological and food waste collected on the island and use it with the final purpose of generating electricity to be used on the island (another large issue on the island is the availability of electricity)

Setting up of a medical waste treatment plant within the anaerobic digestor facility, which would treat such medical waste through shredding and sterilization, which would generate further on plastic waste, which can be used in the above-mentioned plastic waste recycling PPP.

Setting up within the sorting station of a construction waste crushing machine for the hard construction waste (nonbiological) 
At the same time all the above have to be supported with a coercion program implemented by the state, namely fines for not upholding the collection practices, for burning waste, for dumping waste and for depositing waste into pits. These fines have to be high and at the same time replaceable with community work namely collection of waste from public roads.

\section{CONCLUSIONS}

Solutions are global, management is local: This statement is the basis of our analysis, due to the fact that although there are sufficient means of managing the generated waste, it is up to the local management to pick and choose which one is best suited for each situation.

As can be seen from the above, while the same solution could work for both situations, there are barriers to a linear application, barriers which are generated by local customs, financial limitations, degree of culture and "mindfulness of others".

What this means is that while there might be similar conditions for various administrative units, the manner in which a solution is implemented depends on the local factors as one unit might choose a solution another one might choose another solution.

The problem is that any analysis on the solutions to be implemented does not necessary depends on the future impact over the environment, but rather on the immediate solving of a problem. For example, applied on the case under analysis the obvious solution for the waste generated in Zanzibar would be the building of a large incinerator which would act as an energy generator essentially a WTE facility which would take over all the waste generated on the island irrespective of type.

However, such a solution has several disadvantages as follows:

- Extremely high costs for initial set up;

- Low number of involved individuals in terms of employment opportunities since such a facility is mostly automated;

- High costs for the population due to high amortization;

- High costs for the generated electricity, to be paid by the population;

- Long term possible impact over the environment, impact which would be visible solely after 20-30 years in terms of pollution.

There is no activity which would have as purpose the reusage or recycling of the waste.

In conclusion there is no set solution for the case of Zanzibar, due to the fact that although the technological solution can be determined based on the make-up of the waste, there is a large portion determined by the population and their personal view over the problem of waste.

At the same time as mentioned above, the "mindfulness of others" mindset is a must, due to the fact that the entirety of the population has to take into account how their actions have an impact over the rest of the population, over the environment and over their own existence and personal development. All the above analyses can be applied to Romania and any of its administrative units, since the status of the waste management systems is almost on par with the ones in Zanzibar, landfilling and incineration being the preferred solution for some $90 \%$ of generated waste. However an in depth analysis or even a superficial one can only be achieved based on the composition of the generated waste in analyzed administrative units.

\section{REFERENCES}

Chang, N.-B., \& Pires, A. (2015). Sustainable Solid Waste Management: A systems engineering approach, Wiley

Franceschetti, D. (2017). Principles of Sustainability, Call Number: GE196.P75 2017; ISBN: 9781682176078 
Dinh, P. V., Fujiwara, T., Tho, B. L., Song Toan, P. P., \& Minh, G. H. (2020). A review of anaerobic digestion systems for biodegradable waste: Configurations, operating parameters, and current trends. Environmental Engineering Research, 25(1), 1-17. Retrieved October 10, 2020, from https://www.eeer.org/journal/view.php?doi=10.4491/eer.2018.334

Rathoure, A. K. (2019). Zero Waste: Management Practices for Environmental Sustainability, Call Number: TD793.9. Z47 2020

Wheeler, K., \& Glucksmann, M. (2015). Household Recycling and Consumption, Call Number: HD4482. W47 2015; ISBN: 1137440430

Zimring, C. A., \& Rathje, W. L. (2012). Encyclopedia of Consumption and Waste, Call Number: HD4482. E53 2012; ISBN: 1412988195

https://www.oslo.kommune.no/politics-and-administration/statistics/environment-status/waste-andrecycling-statistics/

http://roaid.ro/studiu-de-impact-deseuri-pentru-energie-vizand-insula-zanzibar-republica-unita-atanzaniei/

https://geology.com/world/tanzania-satellite-image.shtml

https://geology.com/world/norway-satellite-image.shtml

https://www.researchgate.net/figure/World-maps-of-waste-generation-type-and-treatment-2015and-2050-National-per-capita_fig2_340427138 